\title{
Implementasi High Availability Cluster Web Server Menggunakan Virtualisasi Container Docker
}

\author{
Muhammad Aldi Aditia Putra*, Iskandar Fitri, Agus Iskandar \\ Fakultas Teknologi Komunikasi dan Informatika, Informatika, Universitas Nasional, Jakarta, Indonesia \\ Email: 1,*aldiaditiaputra@gmail.com, ${ }^{2}$ tekte12001@yahoo.com, ${ }^{3}$ agusiskandar1005@gmail.com \\ $\left.{ }^{*}\right)$ Email Penulis Korespondensi: aldiaditiaputra@gmail.com
}

\begin{abstract}
Abstrak-Meningkatnya permintaan akan kebutuhan informasi dalam internet menyebabkan jalannya beban trafik pada web server semakin banyak. Maka dari itu dapat menyebabkan beban kerja pada suatu layanan web server mengalami kelebihan beban (request), sehingga server tersebut mengalami down (overload). Berdasarkan penelitian terdahulu penerapan load balancing dapat mengurangi beban traffic pada web server. Metode penelitian ini menggunakan load balancing pada server dengan algoritma round robin dan least connections juga single server sebagai pembanding. Parameter yang diukur yaitu throughput, responses time, request per second, CPU utilization. Dari hasil pegujian didapat sistem load balancing Haproxy, algoritma least connection lebih unggul dibandingkan algoritma round robin. Dihasilkan nilai request per-detik sebesar $2607.141 \mathrm{req} / \mathrm{s}$ dan throughput sebesar $9.25 \mathrm{MB} / \mathrm{s}$ untuk least connection, sedangkan $2807.171 \mathrm{req} / \mathrm{s}$ dan $9.30 \mathrm{MB} / \mathrm{s}$ untuk round robin.
\end{abstract}

Kata Kunci: Cluster, Container, Docker, Load Balancing, Web Server

\begin{abstract}
The increasing demand for information on the internet causes the traffic load on the web server to increase. Therefore it can cause the workload on a web server service to be overloaded (request), so that the server is down (overloaded). Based on previous research the application of load balancing can reduce the burden of traffic on the web server. This research method uses load balancing on servers with round robin algorithm and least connections as well as a single server as a comparison. The parameters measured are throughput, responses time, requests per second, CPU utilization. From the test results obtained Haproxy load balancing system, the least connection algorithm is superior to the round robin algorithm. Generated per-second request value of $2607,141 \mathrm{req} / \mathrm{s}$ and throughput of $9.25 \mathrm{MB} / \mathrm{s}$ for the least connection, while 2807,171 req / s and $9.30 \mathrm{MB} /$ $\mathrm{s}$ for round robin.
\end{abstract}

Keywords: Cluster, Container, Docker, Load Balancing, Web Server

\section{PENDAHULUAN}

Meningkatnya permintaan akan kebutuhan informasi dalam internet menyebabkan jalannya beban traffic data pada web server semakin banyak akibat terlalu banyaknya request. Maka dari itu dapat menyebabkan beban kerja pada suatu layanan web server mengalami kelebihan beban (request), sehingga server tersebut mengalami down (overload). Untuk menanggulangi permasalahan beban yang belebihan dalam suatu server maka diterapkannya konsep clustering, yaitu suatu teknologi untuk menggabungkan beberapa server untuk bekerja secara bersamaan yang merupakan seperti satu sistem tunggal. Dalam pengimplementasiannya, clustering web server perlu menggunakan metode load balancing supaya beban traffic setiap masing masing web server dapat berjalan dengan optimal [1].

Sebelumnya berdasarkan penelitian yang telah dilakukan oleh Hasta Triangga dkk dihasilkan bahwa penggunaan algoritma static round-robin lebih efisien. Hal ini ditunjukkan oleh grafik CPU load dimana ketika menggunakan algoritma static round-robin nilai rata-rata yang diperoleh untuk beban CPU sedikit lebih kecil dan throghput lebih besar dibandingkan dengan penggunaan algrotima least-connection, nilai yang diperoleh untuk beban CPU adalah $0.1 \%$; 0,25\%; dan 1.15\% [2]. Penelitian yang dilakukan oleh Maya Rosalia dkk dengan sistem Haproxy load balancer dapat melayani hingga 2352.937 req/s sedangkan pada single virtual server hanya sampai $1428.161 \mathrm{req} / \mathrm{s}$ [3]. Penelitian yang dilakukan oleh Dimas Setiawan Afis dkk hasil throughput yang didapatkan dari load balancing yang menggunakan algoritma least connection dan round robin memiliki hasil yang berbeda. Load balancing yang menerapkan algoritma leastconn memberikan hasil throughput yang lebih baik dari pada algoritma round robin [4].

Berdasarkan perancangan tersebut maka penerapan load balancing pada cluster web server menggunakan virtualisasi container docker dapat lebih efisien. Dikarenakan cluster web server adalah untuk menggabungkan beberapa server dalam satu kesatuan yang saling terhubung satu sama lain dan juga diperlukannya sistem load balancing menggunakan algoritma round robin dan least connection yang bekerja sebagai pembagi beban kerja traffic pada web server. Maka dari itu, untuk meminimalisir terjadinya overload pada web server diperlukannya load balancing web server agar dapat lebih mudah membagi beban kerja secara merata pada sebuah web server dibandingkan dengan menggunakan single server.

\section{METODE PENELITIAN}

Dalam penggunaan web server clustering dibutuhkannya solusi untuk menangani permasalahan yang terjadi pada kinerja suatu web server akibat terlalu banyaknya request dari client sehingga meningkatnya skalabilitas pada 
JURNAL MEDIA INFORMATIKA BUDIDARMA

Volume 4, Nomor 1, Januari 2020, Page 9-13

ISSN 2614-5278 (media cetak), ISSN 2548-8368 (media online)

Available Online at https://ejurnal.stmik-budidarma.ac.id/index.php/mib

DOI $10.30865 /$ mib.v4i1.1729

sistem terdistribusi. Maka load balancing menjadi solusi dalam menangani beban kerja pada web server. Tools yang digunakan pada load balancing adalah HAProxy yang merupakan open source untuk load balancing dan dengan tujuan untuk menangani permasalahn request yang berlebihan pada web server (overload) [5].

\subsection{Kebutuhan Perangkat}

Terdapat beberapa perangkat yang digunakan dalam penelitian dalam perancangan sistem, perangkat yang dibutuhkan terdiri dari hardware dan software diantaranya:

1. Hardware: Laptop Windows 10, Processor i3-5005U, CPU 2.00GHz, RAM DDR3 8GB, HDD 500GB

2. Software: OS Ubuntu Server 16.0 (RAM 2GB memory 16MB pada masing - masing di Ubuntu server).

3. Tools pendukung: HAProxy (tools load balancing) dan Apache Benchmark (tools pengujian load balancing pada web server).

\subsection{Perancangan Desain Sistem}

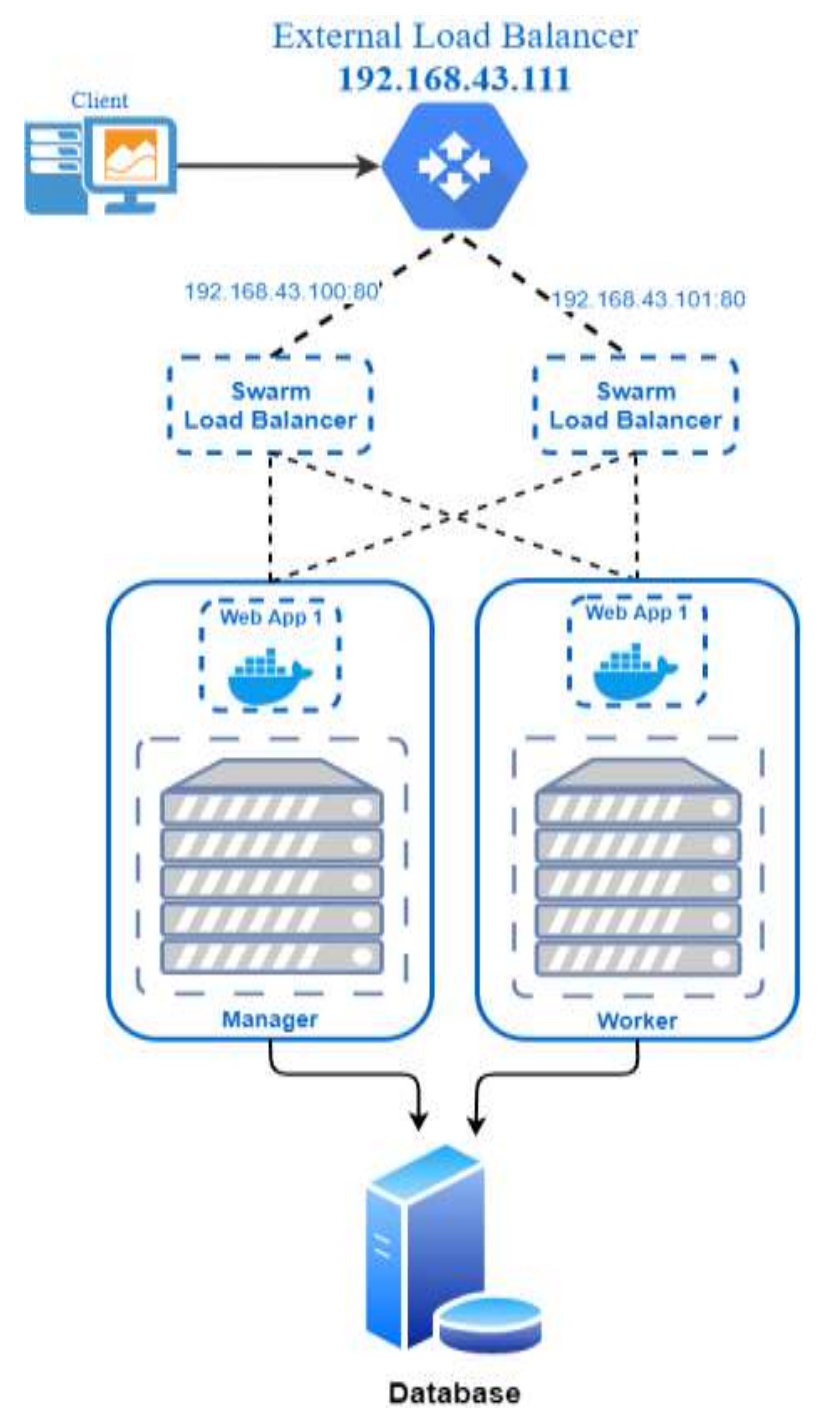

Gambar 1. Perancangan Desain Sistem

Rancangan topologi pada Gambar 1 dibangun menggunakan beberapa server dengan menggunakan konsep clustering yang dimana berguna untuk menggabungkan (replicate) beberapa server menjadi satu kesatuan dan metode yang digunakan dalam clustering adalah load balancing yang ditujukan untuk membagi rata beban kerja pada suatu web server agar tidak terjadi down di salah satu server akibat terlalu banyaknya request dari client. load balancing berperan penting dalam pembagian data yang terjadi di sebuah web server. teknologi virtualisasi dapat lebih mudah membuat sebuah simulasi dari perangkat keras, sistem operasi, dan jaringan. Virtualisasi digunakan sebagai sarana untuk improvisasi skalabilitas dari perangkat keras yang ada, dengan virtualisasi beberapa sistem operasi atau OS dapat berjalan secara bersamaan pada satu buah komputer. Aplikasi docker yang merupakan open source dapat lebih mudah mengemas (replicate) sebuah software aplikasi yang dibutuhkan pada web server dengan wadah yang disebut dengan container. docker sendiri memiliki mode swarm yang digunakan untuk mendistribusikan permintaan pada setiap node - node secara seimbang. Swarm memiliki 2 jenis node, masing - masing node tersebut memiliki peran. Node utama berperan sebagai manager (master) untuk memantau 
JURNAL MEDIA INFORMATIKA BUDIDARMA

Volume 4, Nomor 1, Januari 2020, Page 9-13

ISSN 2614-5278 (media cetak), ISSN 2548-8368 (media online)

Available Online at https://ejurnal.stmik-budidarma.ac.id/index.php/mib

DOI 10.30865/mib.v4i1.1729

kinerja note lainnya. Sementara note yang lain akan berperan sebagai worker, dimana kerja worker tersebut hanya untuk mejalankan tugas dari node manager tersebut. Kelebihan dari Docker swarm adalah jika salah satu service mati maka service akan digantikan dengan yang aktif [6].

Tabel 1. List Container

\begin{tabular}{cccccc}
\hline No & Hostname & Ip Address & Operating System & Memory & CPU \\
\hline 1 & CT1 & 192.168 .43 .100 & Ubuntu Server & $2 \mathrm{~GB}$ & 2 core \\
2 & CT2 & 192.168 .43 .101 & Ubuntu Server & 2GB & 2 core \\
\hline
\end{tabular}

Tabel diatas merupakan spesifikasi yang diperlukan dalam membuat sistem pada container docker dan berapa jumlah container yang diperlukan pada penelitian ini. Semua Container akan diisi dengan web server aplikasi dengan mengetahui pemanfaatan sumberdaya computer dengan menggunakan virtualisasi container docker dan menjalankan serangkaian tes dan uji coba dengan aplikasi docker di virtual-machine dengan metode load balancing pada web server [7].

\section{HASIL DAN PEMBAHASAN}

\subsection{Parameter Pengujian}

Parameter pengujian yang dilakukan pada sistem load balancing, diantaranya: throughput, response time, request per second, dan CPU utilization [8].

1. Throughput

Throughput adalah bandwidth aktual yang terukur pada ukuran waktu tertentu di jaringan. Pengujian pada throughput merupakan parameter variabel dari QoS (Quality of Service) yang ditujukan untuk melihat performansi jaringan dari segi kecepatan pengiriman paket yang dilakukan dengan mengirim dan memanfaatkan bandwidth yang ada.

2. Response Time

Pengujian response time ditujukan guna mengukur seberapa cepat suatu container dapat menerima request dari client.

3. Request per second

Pengujian request per second dilakukan dengan mengirim layanan per satuan detik dari client yang kemudian dikirimkan ke web server untuk mengetahui kinerja server yang menggunakan sistem load balancing.

4. CPU Utilization

Pengujian dilakukan untuk meninjau penggunaan resources oleh container dari sisi CPU (processor) untuk melihat perbedaan penggunaan CPU pada setiap container saat menjalankan load balancing.

\subsection{Skenario Pengujian}

Skenario pengujian dilakukan pada setiap web server aplikasi yang ada dalam container, pengujian dilakukan untuk melihat kemampuan web server dengan load balancing dan web server tanpa load balancing. Dilakukan permintaan (request) untuk menguji kemampuan web server, request yang diuji sebesar 1000, 3000, 5000 dan 7000 [9]. Adapun skenarionya sebagai berikut:

1. Pengujian dengan load balancing menggunakan algoritma Round Robin dan least connections.

2. Pengujian tanpa load balancing menggunakan Single Server.

\subsection{Hasil Pengujian}

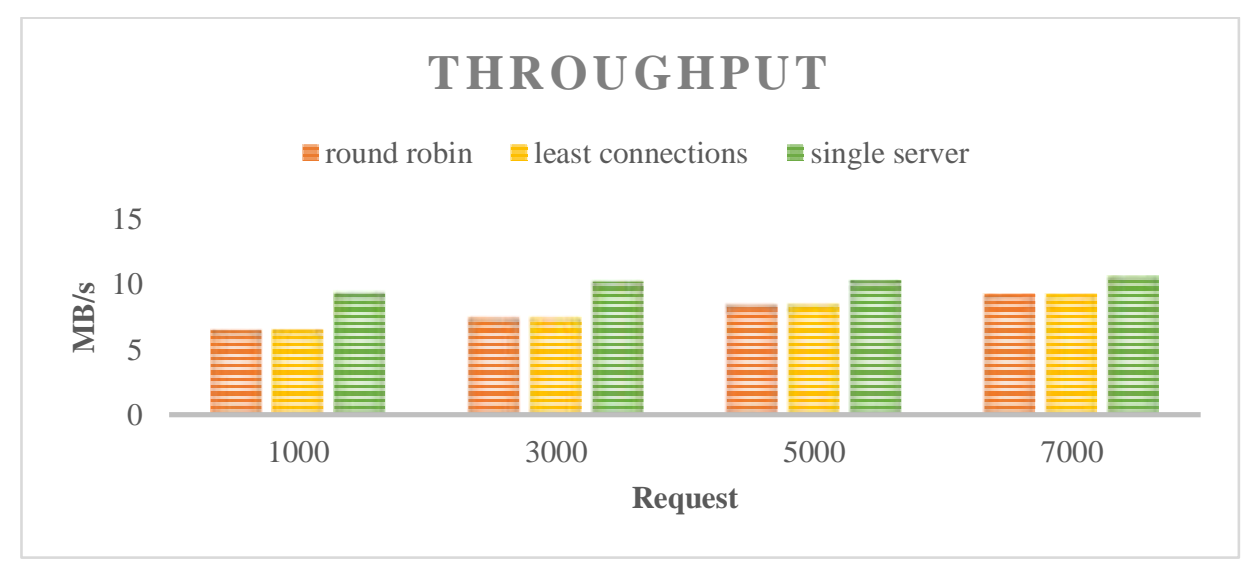

Gambar 2. Hasil Pengujian Nilai Throughput 
JURNAL MEDIA INFORMATIKA BUDIDARMA

Volume 4, Nomor 1, Januari 2020, Page 9-13

ISSN 2614-5278 (media cetak), ISSN 2548-8368 (media online)

Available Online at https://ejurnal.stmik-budidarma.ac.id/index.php/mib

DOI $10.30865 /$ mib.v4i1.1729

Dari diagram diatas menunjukkan apabila nilai throughput naik dikarenakan meningkatnya jumlah beban (request) yang dimasukkan, apabila semakin besar nilai throughput yang diberikan maka performansinya akan semakin bagus nilai throughput yang didapat. Dari hasil pengujian yang dilakukan dengan sistem load balancing menggunakan algoritma round robin dan least connections maka nilai throughput yang didapat secara keseluruhan lebih baik dibandingkan dengan single server, dikarenakan dapat lebih mudah melayani permintaan request yang datang secara bersamaan apabila menggunakan sistem load balancing karena server yang digunakan lebih dari satu server. Maka nilai throughput cenderung baik dengan menggunakan algoritma round robin dan least connections dibandingkan dengan single server. Karena nilai dari hasil maksimal throughput sebesar 9.22 MB/s apabila server tersebut menerima 7000 request dengan sistem load balancing yang menggunakan algoritma round robin pada docker, untuk algoritma least connections sebesar $9.25 \mathrm{MB} / \mathrm{s}$.

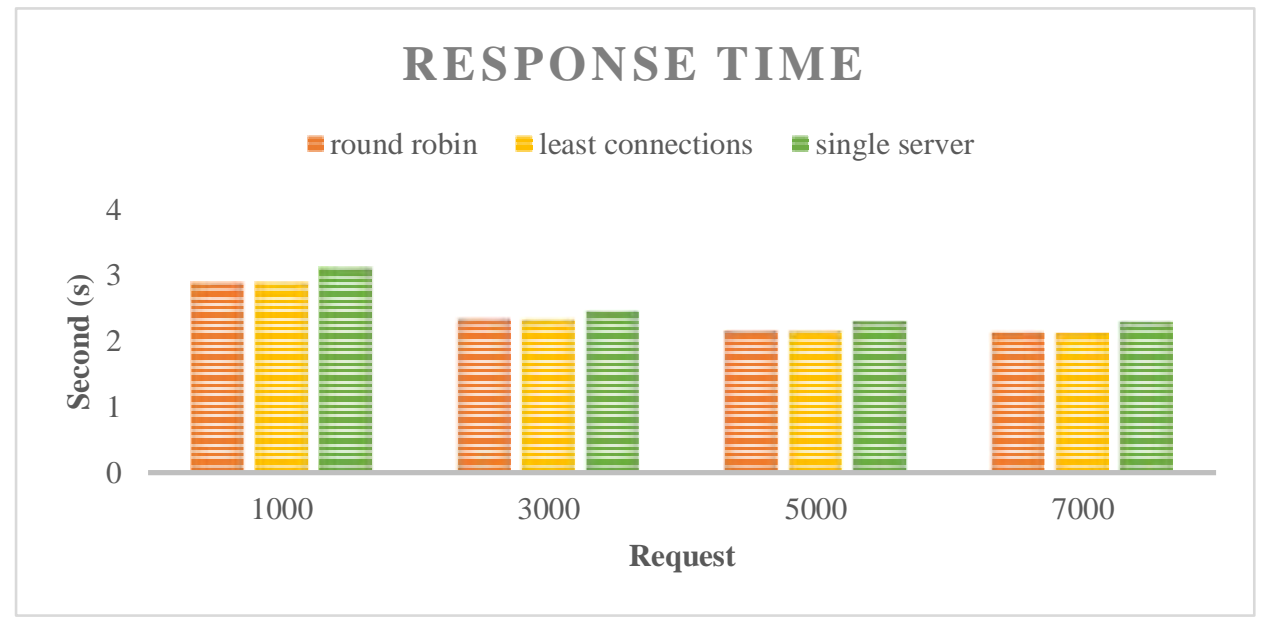

Gambar 3. Hasil Pengujian Nilai Response Time

Hasil pengujian dari 2 server dengan menggunakan round robin dan least connections dapat lebih stabil dibandingkan dengan Single Server. Karena nilai response time yang didapat lebih kecil dengan menggunakan round robin dan least connections, karena single server hanya menggunakan 1 buah web server. maka dari itu nilai response time yang didapat sangat besar dan membutuhkan waktu yang sangat lama apabila mendapatkan request dari client. Berdasarkan nilai response time yang telah diuji rata-rata yang didapat pada sistem load balancing menurun karena nilai throughput yang didapat cenderung naik maka akan lebih cepat untuk mengirimkan response pada client. Dibandingkan dengan response yang didapat pada single server. Nilai response time pada Docker dengan request 7000 data menggunakan algoritma Round Robin yaitu 2,128 second dan algoritma least connections yaitu 2,127 second .

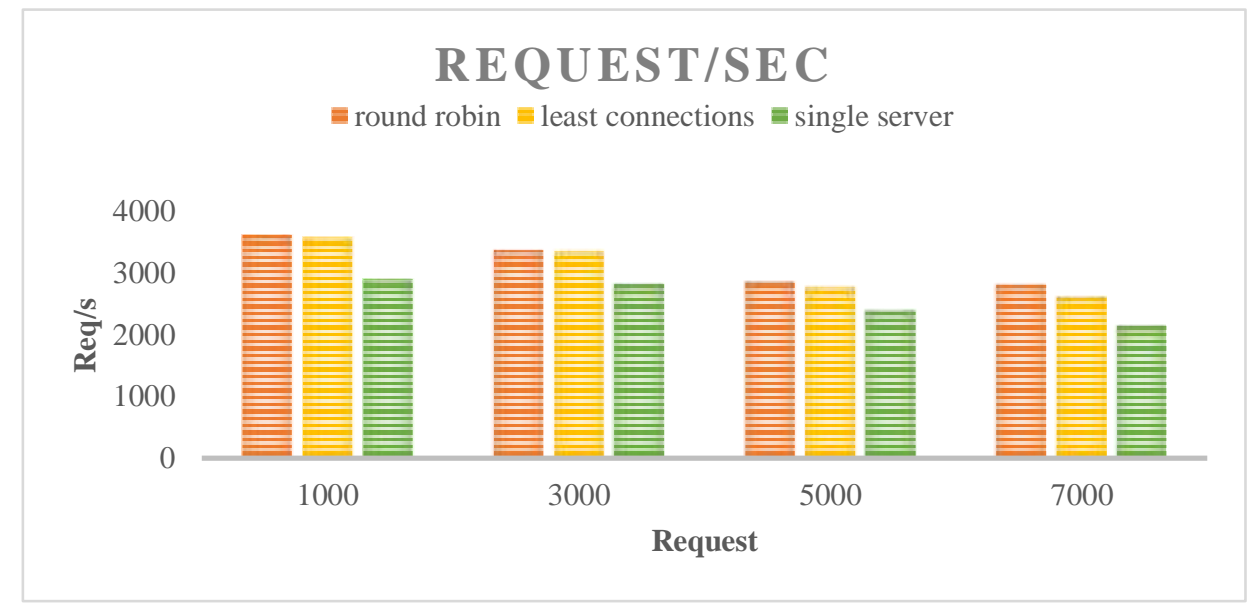

Gambar 4. Hasil Pengujian Request Per Second

Dari grafik diatas menunjukkan bahwa menggunakan round robin dan least connections maka jumlah request yang diterima akan lebih besar,dan performasi dari server juga akan lebih baik. Dikarenakan jumlah user yang semakin meningkat. Hal ini membuktikan bahwa dengan menggunakan round robin dan least connections pada web server, data yang dikirim juga akan dibagi menjadi rata disetiap masing - masing server dibandingkan dengan hanya menggunakan satu single web server dalam menerima permintaan banyaknya request dari client. Dengan menggunakan algoritma Round Robin dihasilkan nilai maksimal yaitu $2807.171 \mathrm{Req} / \mathrm{s}$, least connections dengan nilai 2607.141 Req/s. 


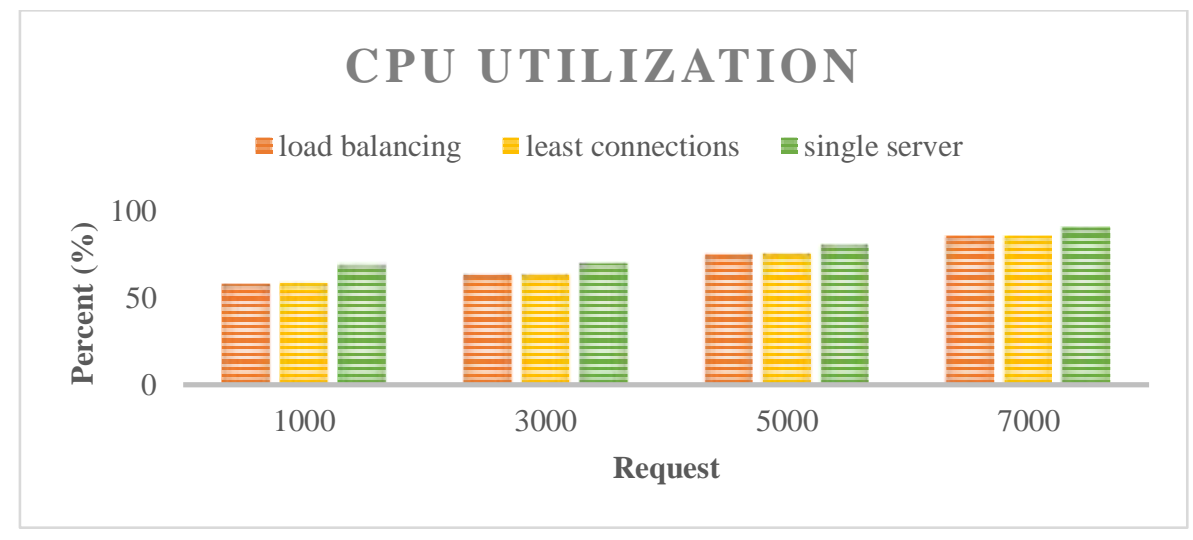

Gambar 5. Hasil pengujian CPU Utilization

Pada pengujian CPU utilization, nilai penggunaan CPU didapat dengan menggunakan aplikasi htop untuk memonitoring resource yang terpakai pada server, Semakin kecil persentase penggunaan CPU yang dihasilkan maka semakin bagus sistem tersebut dan juga semakin ringan sistem tersebut untuk dijalankan pada server [10]. terlihat bahwa Single Server selalu mendapat nilai CPU utilization lebih tinggi dibanding dengan sistem yang menggunakan round robin dan least connections. Hal tersebut disebabkan karena penggunaan dalam single server mendapatkan beban kerja yang jauh lebih tinggi dibandingkan dengan menggunakan round robin dan least connections. Terjadi penurunan pada sistem load balancing dengan menggunakan algoritma round robin dan least connections karena beban kerja dibagi secara merata pada server lainnya dan tidak terpusat pada satu buah web server. Maka menggunakan konsep clustering web server pada virtualiasasi container docker akan menghemat penggunaan resource yang ada.

\section{KESIMPULAN}

Berdasarkan pengujian yang dilakukan, dapat disimpulkan bahwa:

1. Ditinjau dari segi performansi, kemampuan sistem load balancing dengan dua buah web server cluster dalam melayani request client jauh lebih baik dibandingkan dengan Single Server, karena mengacu pada konsep cluster computing dimana penggunaan cluster dalam sebuah server tidak membebankan atau terpusat pada satu server saja sehingga tidak memberatkan server.

2. Pada sistem load balancing Haproxy, algoritma least connection lebih unggul dibandingkan algoritma round robin. Dihasilkan nilai request per-detik sebesar $2607.141 \mathrm{req} / \mathrm{s}$ dan throughput sebesar $9.25 \mathrm{MB} / \mathrm{s}$ untuk least connection, sedangkan $2807.171 \mathrm{req} / \mathrm{s}$ dan $9.30 \mathrm{MB} / \mathrm{s}$ untuk round robin.

3. CPU Utilization yang didapat dengan menggunakan load balancing menggunakan algoritma round robin dan algoritma least connections menghasilkan nilai total yang lebih kecil dibanding single server.

\section{REFERENCES}

[1] Y. T. Sumbogo, M. Data, dan R. A. Siregar, "Implementasi Failover dan Autoscaling Kontainer Web Server Nginx Pada Docker Menggunakan Kubernetes," J. Pengemb. Teknol. Inf. dan Ilmu Komput. Univ. Brawijaya, vol. 2, no. 12, hal. 6849-6854, 2018.

[2] H. Triangga, I. Faisal, dan I. Lubis, "Analisis Perbandingan Algoritma Static Round-Robin dengan Least-Connection Terhadap Efisiensi Load Balancing pada Load Balancer Haproxy,” J. Nas. Inform. dan Teknol. Jar., vol. 4, no. 1, hal. 70-75, 2019.

[3] M. Rosalia, R. Munadi, dan R. Mayasari, "Implementasi High Availability Server Menggunakan Metode Load Balancing Dan Failover Pada Virtual Web Server Cluster," e-Proceeding Eng., vol. 3, no. 3, hal. 4496-4503, 2016.

[4] M. Rexa, M. Bella, M. Data, dan W. Yahya, "Implementasi Load Balancing Server Web Berbasis Docker Swarm Berdasarkan Penggunaan Sumber Daya Memory Host," vol. 3, no. 4, hal. 3478-3487, 2019.

[5] D. S. Afis, M. Data, dan W. Yahya, "Load Balancing Server Web Berdasarkan Jumlah Koneksi Klien Pada Docker Swarm," vol. 3, no. 1, hal. 925-930, 2019.

[6] T. P. Kusuma, R. Munadi, dan D. D. Sanjoyo, "Implementasi dan Analisis Computer Clustering System dengan Menggunakan Virtualisasi Docker," e-Proceeding Eng., vol. 4, no. 3, hal. 1-6, 2017.

[7] M. F. R. Bik, "Implementasi Docker Untuk Pengelolaan Banyak Aplikasi Web (Studi Kasus : Jurusan Teknik Informatika UNESA)," J. Manaj. Inform., vol. 7, no. 2, hal. 46-50, 2017.

[8] R. A. Pratama, R. Mayasari, dan D. D. Sanjoyo, "Implementasi Web Server Cluster Menggunakan Metode Load Balancing Pada Container Docker, Lxc, Dan Lxd," e-Proceeding Eng., vol. 5, no. 3, hal. 5028-5035, 2018.

[9] M. A. Nugroho dan R. Kartadie, “Analisis Kinerja Penerapan Container untuk Load Balancing Web Server," JIPI (Jurnal Ilm. Penelit. dan Pembelajaran Inform., vol. 1, no. 02, hal. 7-15, 2016.

[10] R. Li, Y. Li, dan W. Li, "An Integrated Load-balancing Scheduling Algorithm for Nginx-Based Web Application Clusters," J. Phys. Conf. Ser., vol. 1060, no. 1, 2018. 